\title{
Urban agricultural and sustainability program at Houston's downtown university: Combining new curriculum, hands-on projects, and a hurricane
}

\author{
Lisa Morano ${ }^{a} *$ and Vassilios Tzouanas ${ }^{b}$ \\ University of Houston-Downtown
}

Submitted September 13, 2017 / Accepted September 13, 2017 / Published online October 17, 2017

Citation: Morano, L., \& Tzouanas, V. (2017). Urban agricultural and sustainability program at Houston's downtown university: Combining new curriculum, hands-on projects, and a hurricane. Journal of Agriculture, Food Systems, and Community Development, 7(4), 23-33.

http://dx.doi.org/10.5304/jafscd.2017.074.003

Copyright (C) 2017 by New Leaf Associates, Inc.

\begin{abstract}
The University of Houston-Downtown (UHD), a Hispanic-serving institution, launched an educational program in 2016 that engages undergraduates in a summer curriculum with a hands-on project focused on urban agriculture and sustainability. The goals are to deliver new content, create purposeful interdisciplinary teams, and engage the participants, who are largely students of color, through mentoring and professional-development activities. In this reflective essay, we discuss improvements made between the first and second year and program elements that were most effective. The 2017 cohort was simultaneously engaged in two courses and the creation of an
\end{abstract}

a * Corresponding author: Lisa Morano, Department of Natural Sciences, University of Houston-Downtown, One Main Street, Houston, TX 77002-1001 USA; +1-713-221-2782; moranoL@uhd.edu

b Vassilios Tzouanas, Department of Computer Sciences and Engineering Technology, University of Houston-Downtown, One Main Street, Houston, TX 77002-1001 USA. aquaponics system. Each student group created a system that could grow fish and hydroponic plants using solar energy. Qualitative student survey results indicate that the program increased student knowledge and affected career directions. The program was designed to extend mentoring from the summer through fall to optimize projects and prepare students for presentations on and offcampus. However, these plans had to be modified as Harvey, the most damaging hurricane in U.S. history, flooded the school and destroyed the student aquaponic systems. Fall plans now include rebuilding a single aquaponics system and consideration of resiliency in future sustainability initiatives. The most critical elements of this

\section{Disclosures}

The authors would like to acknowledge funding from the USDA NIFA (Award number 2015-38422-24081). In addition, we would like to acknowledge funding from the University of Houston-Downtown through support from the College of Science and Technology and from the Center for Teaching and Learning Excellence. 
program have been shown to be students' intense immersion in curriculum and projects, creating cross-disciplinary student groups, mentoring across the program, and, finally, maintaining flexibility. The hurricane's incursion into our program also stands as a powerful backdrop for discussions not only at our university but nationally of how we create sustainable communities and agricultural systems in a world that will continue to experience climatic changes.

\section{Keywords}

Urban Agriculture; Undergraduate; Aquaponics; Hydroponics; Curriculum; Mentoring; Hurricane; Sustainable Development; Renewable Energy Systems; Resilience; Climate Change

\section{Introduction}

This is a reflective essay about a recent collaborative summer program at the University of Houston-Downtown (UHD). The two faculty mentors who designed this program come from different departments. Lisa Morano is faculty in the Department of Natural Sciences with an ecology and agricultural background, and Vassilios Tzouanas is from the Department of Computer Science and Engineering Technology with a chemical engineering and sustainable energy background. We planned to develop a collaborative summer program for undergraduates that combined curriculum and a hands-on project to accomplish several goals. First, we wanted to expose students to challenges and technical solutions to address urban agriculture and sustainability. These topics are not covered in standard biology or engineering technology curriculum. Second, we wanted students to work together in cross-disciplinary teams. This is the reality students will encounter when they enter the workforce, and we wanted to include it in their educational experience (Clark, 2006). The 2017 cohort worked in groups to build solarpowered aquaponic systems in the UHD Sustainability Garden. Third, we wanted our program to develop soft skills and student confidence so our students would be more successful in their future careers. Given the devastating flood that has just impacted the entire Houston region, a fourth goal is emerging. This goal will be to model resiliency for our students and consider the role of resiliency in teaching about and creating sustainable systems.

Houston is the ideal place to educate the next generation about urban agriculture and sustainability. Houston is the fourth largest city in the country and the fastest growing large city in the U.S. Houston is also the most diverse city in America (Mejia, 2017, p. 2). Houston is home to numerous colleges, including private universities and a large multi-institutional medical center. The University of Houston system is the regional public university system, which comprises four separate universities, each with its own mission and population. UHD is the urban university at the heart of Houston. It is a commuter university with over 14,000 students, and its diversity matches the city of Houston. The UHD student body is $46 \%$ Hispanic, 23\% Black, 17\% White and the remaining percentage is Asian and other ethnicities (UHD, 2017). The student body also includes a number of nontraditional students returning to college to finish their degree. Approximately $80 \%$ of the students are eligible for Pell grants, which indicates that they are on average below the official federal poverty threshold. The mission of UHD includes a focus on academic and career preparation, and it is an inclusive community dedicated to integrating research, teaching, and community service (UHD, 2016).

Like many urban, commuter schools, UHD has challenges. Urban students have limited time as many are working full- or part-time and may have families. Serious time constraints negatively affect their ability to take advantage of opportunities (Hammer, Grigsby, \& Woods, 1996). We have made several additional observations about UHD students. First, they do not have access to information about agriculture or sustainability. Texas does have large schools that specialize in these subjects, but they are the larger land-grant universities. These universities are often not an option for urban students who may not be able to leave home, have limited financial resources, have not had adequate high school preparation for entrance, or who are coming back to school. Second, we know that our students learn well through handson projects that are related to coursework. The reality is that this approach works well for all 
students by engaging them in active construction of the concept and increasing social interaction (Krajcik \& Blumenfeld, 2006). Finally, we know that many of our students lack the confidence and professional-development skills to pursue jobs for which they may be well suited. Many students at UHD are the first in their family to go to college. Our students, like other first-generation and lowincome students, often perceive early failures as a lack of ability on their part rather than a step in the process of learning (Thayer, 2000). We also know students are often unclear about how to get into graduate school or enter the professional job market. Mentoring can be a critical component of academic success (Jacobi, 1991), and we know from personal experience it builds student confidence and give students personalized information vital for professional success. The challenge is to scale up the typical one-on-one mentoring to influence more students.

One additional motivation to build our collaborative program grew from a critical social justice issue in Houston. Its poorer neighborhoods are likely to be in food deserts. These food deserts are usually in impoverished neighborhoods and are defined as regions of limited fresh or healthy foods due to a lack of grocery stores or other food providers (U.S. Department of Agriculture, Economic Research Service [USDA ERS], n.d.). The problem is not a simple one to fix. Food deserts are complex and have economic, transportation, social, and educational components to be addressed. As with all problems, the most effective way to implement change is from within the neighborhoods. Many of UHD's students live within Houston's food deserts areas. As an urban university, one of our obligations should be to give the students who live in food deserts the knowledge, skills, and confidence they need to be the future leaders in their communities. Our long-term goal through education is to give students the tools to translate what they have learned into action and to make change in their neighborhoods.

Natural disasters are the ultimate reminder that humans are inhabitants, not legislators, of the planet. Western culture has numerous narratives about the interactions of humans on the planet.
There is the narrative that the pristine earth has been trampled and what remains should be protected and preserved; there is the narrative that humans have a right and dominion over the planet's resources for our own gain; and there is the narrative that science, technology, and capitalism can be aligned in partnership with nature to create a path toward a sustainable future (Merchant, 2013). Resiliency is also a critical ingredient in the model of a sustainable future (Klotz, 2016). How resilient are our cities, industries, and approaches to problem-solving in a world that will get warmer and reach 9 billion people in the next generation? Given the hurricane that struck the Houston area in August 2017, the role of resiliency in creating sustainable programs and systems will need to be incorporated into our discussions and design of our current and future programs at UHD and more broadly in the Houston region. The scientific data predicts that global warming will bring more disasters and warmer oceans will bring more devastating storms (Intergovernmental Panel on Climate Change, 2012). This will affect all future jobs, but it is particularly critical that students pursuing jobs related to sustainability have the skills to analyze data and build solutions that account for such a future.

Hurricane Harvey and the subsequent tropical storm will likely serve as a valuable backdrop to teaching resiliency and sustainability. Harvey dropped between 40 and 50 inches $(102$ to $127 \mathrm{~cm})$ of rain in the Houston area over four days at the end of August 2017 (National Hurricane Center, 2017). Houston does have engineering for flood events, but the region is unquestionably flat and has experienced enormous development over the last two decades. Subsequently, the region was overwhelmed; it was estimated in early September that 33,800 people had to flee to shelters (Federal Emergency Management Agency [FEMA], 2017). Every resident of the region was impacted. UHD was flooded to its first floor, and the student aquaponic systems built in the summer of 2017 and most of the UHD Sustainability Garden were swept away. It will be impossible to ignore the impacts of the storm on our university and our students. As academics, we must model the path 
forward of resiliency in action. We will work with students to rebuild the garden and the aquaponics systems. We will incorporate discussions of resiliency in creating the most sustainable systems of food, energy, and housing for both Houston and our future world.

\section{Methods: Program Logistics}

\section{Program Initiation}

UHD established the Center for Urban Agriculture and Sustainability (CUAS) two years ago with funding from a USDA National Institute of Food and Agriculture (NIFA) grant. This grant runs for four years and supports the creation of a new curriculum at UHD and a summer Experiential Learning through the Center for Urban Agriculture and Sustainability (EL CUAS) program. EL CUAS involves 10 students each year for an intense summer program that has obligations both in the spring before and the fall following the program. This is our second year of EL CUAS, and we will use the 2017 program as the reference and where applicable describe changes made between 2016 and 2017 to improve the program.

We advertise the program in the fall through digital fliers and direct encouragement of students we know. We meet with students a couple times prior to the start of the summer program to discuss logistics. The summer program lasts half the summer and requires students to be on campus daily from 9:00 a.m. to 5:00 p.m. In 2017 students were engaged in two summer courses, hands-on creation of a sustainable system, and professional-development activities. Students receive a stipend of US $\$ 2,000$ for engaging in the program, which they can use to cover the cost of courses or for living expenses while engaged in the full-time program.

\section{Design of the Curriculum}

We designed two courses that were incorporated into the summer program. The courses are SUST 2301, Fundamentals of Sustainability and SUST 3301, Renewable Energy Systems. These courses will also be included in a new minor in sustainability offered by UHD. Therefore, the courses are not only a requirement of the summer program, but they also count toward the minor, should students choose to pursue further sustainability studies. Topics covered in Fundamentals of Sustainability include economics, planetary boundaries and climate change, social inclusion, education, food security, healthcare, resilient cities, and sustainable development. The Renewable Energy Systems include modules on the history, design, and engineering technology of wind, solar, and geothermal energy, and biofuels. The courses have limited prerequisites (second semester English) and no hidden science prerequisites so that they are open to any major. In summer 2017 the courses were taught on alternating days in the summer. The hands-on project of building a renewable system was linked to the curriculum of each course such that each course required a group project, group report, and oral presentation. There was also fluidity between the class and the lab space where projects were assembled so students could apply theory from class, such as how to connect up a solar panel to generate power (Figure 1).

\section{Hands-on Project}

In spring of 2017, the 10 students in the program met to decide on a summer project. The requirements were to build a system that would help solve a food scarcity issue in an urban environment while being sustainable with respect to energy consumption. The group settled on building solar-powered aquaponic systems that would allow students to raise fish in a tank and then use the waste from the fish to fertilize hydroponic plants. The students were assigned to three groups; each group had to design, build, and evaluate its system. Each group had students that were biology majors and engineering technology majors, and one group had an interdisciplinary studies major. Not only was completion of the system an obligation of the summer program, but also it was incorporated into the curriculum of the two courses. The two faculty mentors also applied for and were awarded a highimpact practices internal grant from the UHD Center for Teaching and Learning Excellence. This internal grant allowed for a budget of US $\$ 1,000$ per group to build their system. Students were required to create a preproposal and detailed budget early in the program and to make a final report and oral presentation at the end. 


\section{Professional Development}

Several professional-development activities were incorporated into the program. In 2017 we took a field trip to a Houston high school where a teacher had established a successful aquaponics system. We also took a field trip to the regional Texas AgriLife Extension office to learn about the research experiments and community-engagement activities in which the extension officers participate. On Fridays we established a pot-luck lunch meeting with guest speakers. The goal of all of these activities was to create a relaxed atmosphere where faculty and students could interact with each other and the guests. Guest speakers included the director of the UHD Career Center, who talked about building a résumé, networking, and landing an interview; the director of the UHD Center for Critical Race Studies and faculty of English, who discussed diverse perspectives and the power of writing; the director of the UHD Center for Public Deliberation, who led a discussion on interpretation of data and the role of public deliberation in creating positive community action; and the assistant vice president for the Office of Research and Sponsored Programs, who led a discussion in mastery versus performance-based goals and their role in professional success.

\section{Changes from 2016 to 2017}

At the end of 2016, we scrutinized our program for areas of improvement. We wanted to improve the interaction across disciplines. In 2016 we had science projects (growing plants, extracting DNA, and testing plants for the presence of GMOs) and engineering technology projects (building solar irrigation systems in a community garden). We observed that the students segregated by discipline and it was difficult to maintain the integration of

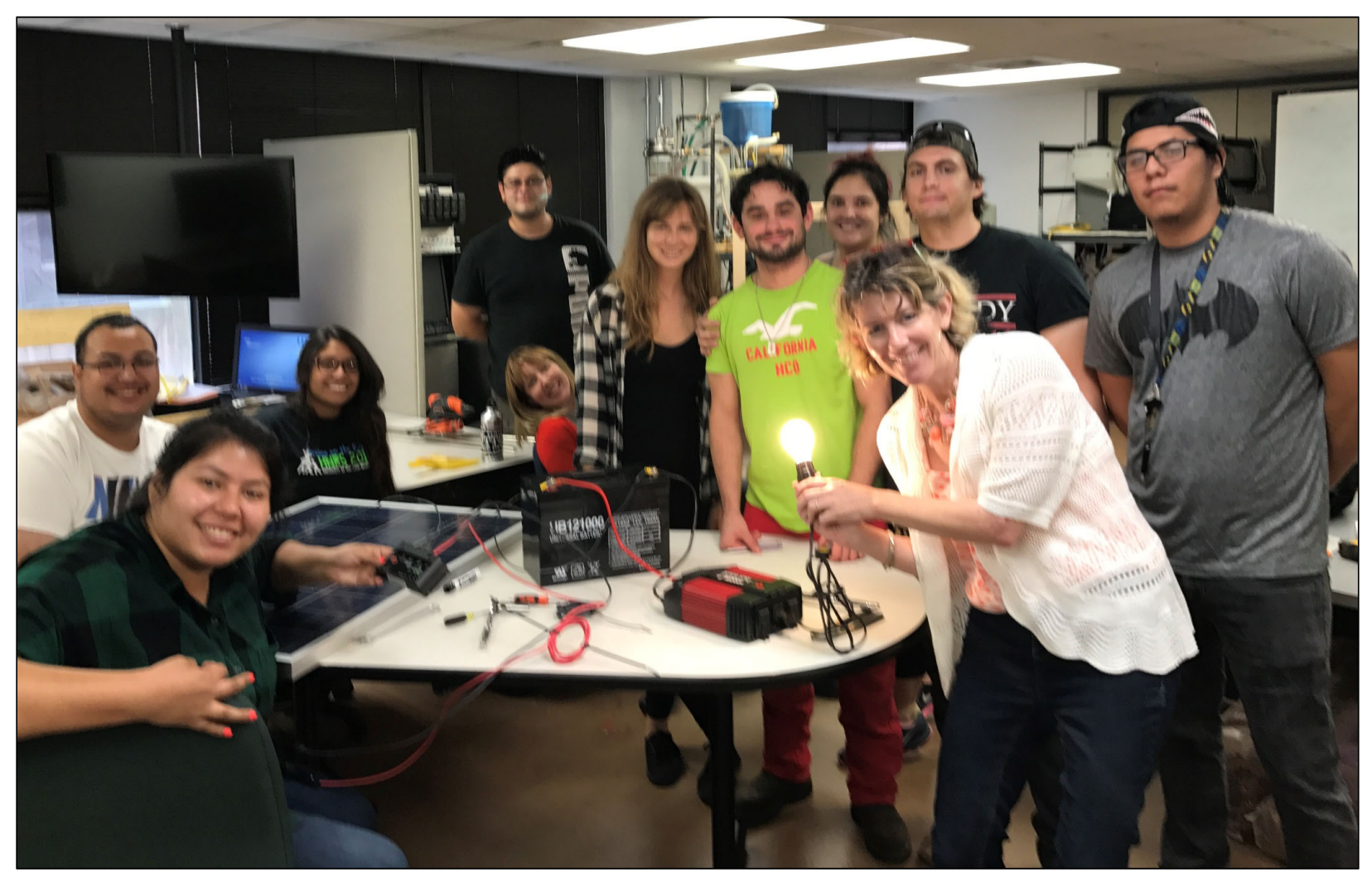

Figure 1. Photo of 2017 Program Participants

Clockwise from front left: Jennifer Herrera, Jonathan Garcia, Yarmilla Reyes, Brayan Calvo, Sara Lyons, Andrea Hain, Isaias Gonzalez, Sarah Graeber, Glen Wood, Sergio Diaz, and Lisa Morano. 
students by major. To address this, we created more purposeful mixed groups in 2017, and the groups were given the combined assignment of building a system with specific biological and engineering requirements. In 2016 the curriculum was in the spring semester before the summer program. In 2017 the curriculum was incorporated into the daily activities of the program so that the hands-on project and concepts in class reinforced each other. In 2017 we also were awarded the internal grant funds which allowed us to give each team a supply budget to manage.

\section{Program Outcomes}

Program recruitment has been most successful by word of mouth and personal outreach to students in our classes. A personal email or conversation with a student appears vastly more effective than blanket emails or digital screen advertisements around the campus. It is a program goal to include students from across the entire university, but personal recruitment has resulted in student cohorts heavily represented by biology and engineering

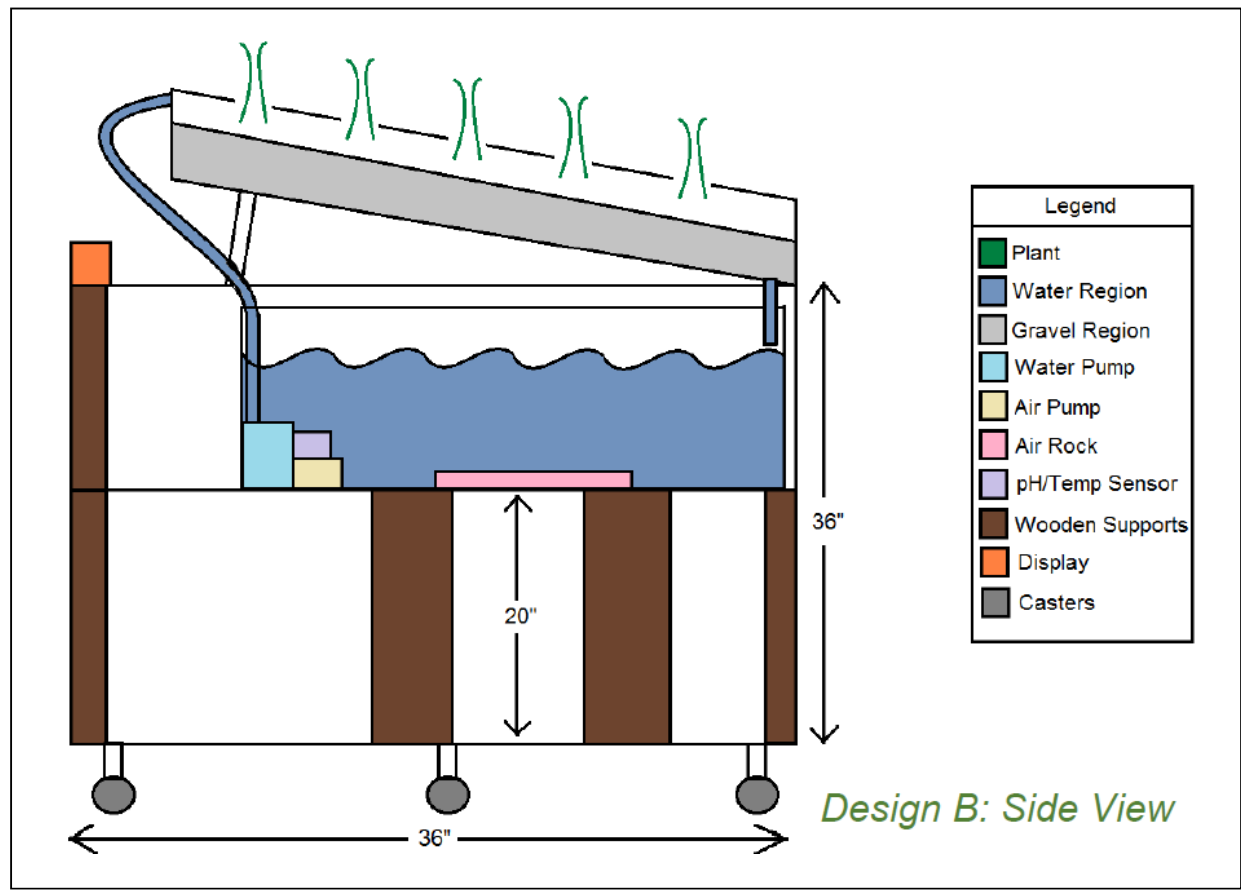

Figure 2. Sample Schematic of Student-designed System that Will Support Fish and Hydroponic Plant Growth

This is the schematic proposed, designed, and built by students Glen Wood, Jonathan Garcia, and Jennifer Herrera. technology majors. We need to determine effective ways to reach students outside the programs where we teach.

The 2017 integration of majors into assigned groups has created cross-disciplinary teams that fostered more cohesive teamwork. Each group was given specific instructions that the entire group must be involved in the engineering and biological functionality. We introduced the mixed groups with complete transparency, explaining that one of the goals was for each member of the team to gain knowledge and skills that others may be better at (e.g., calculations, electrical work, knowledge of the nitrogen cycle). These explicit instructions created a positive learning environment. Students also all worked on their projects in one large engineering lab, and this appeared to create a more cohesive experience than was observed the previous year, when students were separated.

Combining course curriculum and the project resulted in strong engagement in the content and a high quality of projects. In our first year we taught the required curriculum in the spring prior to the summer program. With the required courses held during the summer, the students were not distracted by other courses. The requirement that students and faculty be engaged in an all-day program allowed the faculty to offer bonus lunch-time lecture reviews to make sure no one fell behind in the curriculum. Linking of the coursework to the project improved the engagement in the curriculum. Making the project a large portion of the course grade and including project benchmarks in class 
kept the projects progressing and resulted in very professional aquaponic systems at the end of the program. Each student group settled on a final design that had to be drawn up in schematic form (Figure 2). Each design was a unique design on a pump system that would take the fish waste, pump it through an area to grow plants, and then return the clean water to the fish. Completed systems were all functional and connected to solar-power panels placed in the UHD Sustainability Garden.

Complete immersion in the curriculum and project also allowed us to cover a great deal of content and to have discussions where content in courses intersected or applied to the project. Students used calculations from the Renewable Energy Systems class to determine how much solar power they would need from their system and how the cost of this system compared to systems that use fossil fuels. In Fundamentals of Sustainability, students learned about the complex interdependence of environmental science and growing food, social justice issues related to creating equitable, sustainable systems, and the role of economics in making sure a sustainable system will be adopted. The degree to which the program shifted knowledge was measured by the external evaluator for the program. The students' ability to define "sustainable resources" went from a baseline of $50 \%$ to $100 \%$, "ethical labor practices" went from $50 \%$ to $80 \%$, "renewable energy" went from $80 \%$ to $100 \%$ and "urban agriculture" went from $40 \%$ to $100 \%$.

The program shifted students' interest toward sustainability and urban agriculture. There was an increase in the number of students interested in pursuing the minor in sustainability. A few students are seniors and will not have time to include the sustainability minor in their degree before graduation. Of the remaining seven students, five plan to pursue the minor. There was also a shift in career goals. Five of the students plan to pursue graduate school or medical school, and all have indicated an interest in sustainability, conservation, or sustainable public health. Of the five students planning on industry careers, there was also a major shift in their interests. At the start of the program none of the five industry students was interested in sustainability or agriculture, but at the end three stated they have career goals such as "scientist working in food or agricultural sciences," "engineering position with renewable energy resources," or "a job in a renewable energy industry."

Students encountered many real-life issues that occur when teams must work together to accomplish a task. Some supplies were not available when promised, some original design features were not compatible with living fish or plants, or materials used in the design did not work as expected. For each problem, the group met with mentors to evaluate and choose modifications. Students had to work in groups with members from diverse backgrounds and had to learn to listen to potential issues or solutions from different perspectives. Likewise, students had very different personalities, and with such a tight timeline strong personalities created tensions that had to be talked through. To create a spirit of good communication we met almost every morning to discuss challenges of the previous day, plans for the day, adjustments that needed to be made, and responsibilities that had to be taken.

There is strong evidence that the program improved the students' confidence and ability to work as part of an interdisciplinary team. In response to a question about the item that would most stick with you, one student responded, "Cooperating with different disciplines." In response to general comments, one student said, "This program was an overall great experience, by collaborating with peers outside my discipline it allowed me to gain a new perspective"; another said, "It was a very good opportunity to collaborate with students and faculty that I otherwise would not have had." Of course, putting students in diverse, interdisciplinary teams can have its challenges. One student commented, "Make sure all participants have time to actually work on projects. Credit should not be given to those who made little to no effort to complete the project. Peer evaluations should be done." This is a challenge in mixed groups with an intense summer program, and the peer evaluations will be added next year.

One of our initial goals was to expose students to the reality and complexity of sustainability and urban agriculture. We hoped to expose 
students to data related to climate change, biodiversity loss, population growth, and resource use, and to the potential role of technology in addressing these challenges. When asked about the impact of the program, the cohort from 2017 made the following comments:

"It opened my eyes about the state of the planet."

"We have the power to change things for our communities. This program completely changed my viewpoints on environmental issues and convinced me that we have the power to change the world."

“This program was a great opportunity to learn new techniques as well as have handson experience. While learning certain topics in class, we were able to apply what we learned to make our project more sustainable."
“This program surpassed all my expectations. I came out with a completely different view of the world and changed the industry I would like to work for."

"I loved this program very much. I learned a lot about sustainable practices and energy sources. The need for change in our current world is needed if we want to protect our environment and if we want to protect our environment and if more people learn about this, maybe something can happen sooner."

\section{Results: Impacts of a Hurricane}

The end of August 2017 brought a hurricane and devastating floods to the region. The 2017 projects were completed in July. The original plan was to continue optimizing the aquaponic systems throughout the fall semester; all the student groups were encouraged to apply for Student Government Association funds to continue their work throughout the fall. All three groups were awarded some funds to do this. One month after completing the

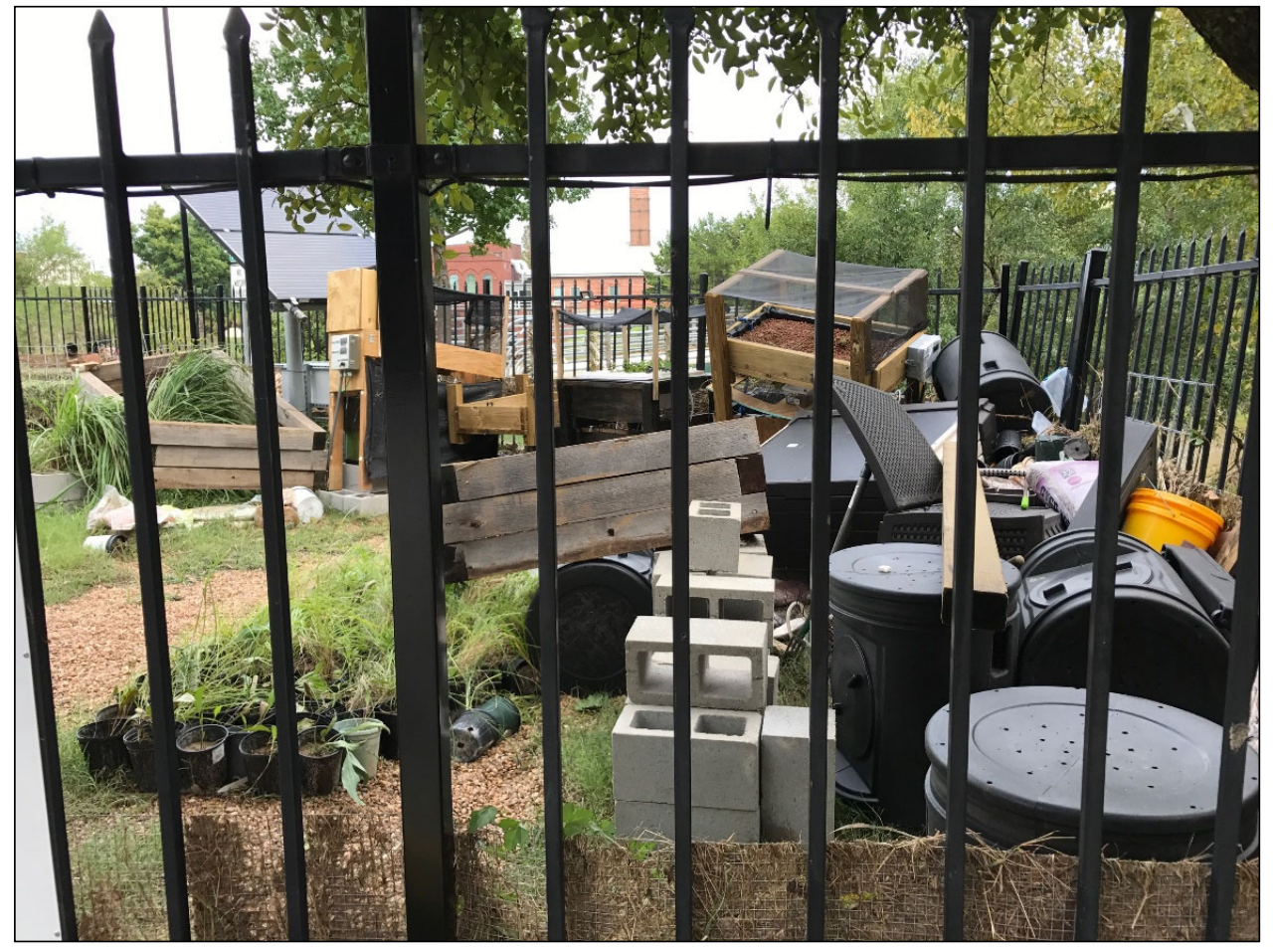

Figure 3. Photo of the UHD Sustainability Garden after it Was Ravaged by Hurricane Harvey

The storm destroyed the aquaponic systems and damaged other features of the garden. systems, however, Hurricane Harvey swept through the UHD Sustainability Garden, dismantling the garden and destroying the aquaponic systems (Figure 3). A result of this flood will be a change in direction for the project. After students who have been impacted have found a safe place to live and the university reopens, we will work with our students to rebuild the aquaponics systems. Our preliminary plan is to build one central system using all the knowledge gained from building the 
individual systems. We will mentor this cohort of students through the chaos of the coming semester and engage them in discussions about the intersection of natural disasters and the creation of sustainable systems.

\section{Discussion: Critical Elements for Building an Undergraduate Program in Urban Agriculture and Sustainability} Intense immersion of students in curricula from two classes, including a hands-on project and professional development activities, can be a powerful tool for student engagement in urban agriculture and sustainability, but also poses some challenges. Students in this program learned about the scope of issues in Fundamentals of Sustainability, and they problem-solved solutions in Renewable Energy Systems. Concepts were reinforced with the hands-on project of building a solarpowered aquaponics system. This intense summer program also included lunchtime review sessions and Friday guest speakers, allowing time to discuss and apply the content in a number of contexts. The intensity of such a program requires that the group meet at least once a day to discuss all aspects of the program including the status of supplies, communication between members, responsibilities of each group member, accomplishments for the day, and goals for the next day. Even with this focus on communication, there may be students who feel they are doing more work than others. Peer evaluation may help with this. The intensity of our program's design resulted in tired students and faculty by the end of the program. Stretching the program from half a summer to a whole summer may alleviate exhaustion, but the half-summer design allows students the flexibility to work before the fall semester or to take other courses that may be required for their degree. If we moved the program to an entire summer as is typical of other universities, we fear we would lose many of our urban students.

Cross-disciplinary programs can be challenging to establish but have a significant payoff. After working together on a previous collaborative project in sustainability, the two mentors of this program wrote a cross-disciplinary
USDA grant that received funding. The collaboration between biology and engineering technology is leading to additional creative ideas. It is likely that collaborations across numerous fields relevant to urban agriculture and sustainability would be just as productive. Those considering such a collaboration should not underestimate the initial time needed to align approaches in different disciplines. For example, the scientific method and engineering approach of design and optimization are distinct and must be reconciled. Engineering and science students (and faculty) speak different languages, and this creates challenges in working together. Working together can be slow initially and can complicate group dynamics, but participants ultimately reach a new level of communication and learning. We are confident this cross-disciplinary program will help students get more job interviews and give them advantages once they land jobs.

Mentoring a program of 10 students with two faculty members can be an effective method for impacting students. The intensity of the program was combined with as much mentoring as possible. We tried to listen to all students daily. We helped students directly with issues that came up, such as advising, financial aid, and plans after graduation. We created forums to learn about each other. This often occurred around food. Almost daily there was a shared breakfast, and faculty and students shared homemade dishes for Friday pot-luck lunches. The goal was to create an environment where students felt supported and inspired.

We have realized it is critical to think through some logistics of the program as it relates to facilities and staff and school policies. We learned there were many questions to consider before the design of the program. Is there a designated person or persons to help students order supplies and make sure they can be obtained fast enough for students to build projects over half a summer? Not only does said person need to be identified, but his or her boss must approve of the time required. Where will students work on the project? If the students will be building, what tools will they need? What safety training will they need to use these tools? Can the equipment be used without 
annoying neighboring classes or setting off fire alarms? What is the required travel paperwork, and can it be done before the program starts? Finally, what funds can be used to support students when they engage in such a program? We are currently using funds from a USDA grant and are exploring ways to keep student stipends going using CUAS funds. It will be critical to have funds to run this program and provide stipends so that students can justify the time the program takes away from working.

We would advise prospective program organizers to be prepared for the unexpected. It is unlikely that others creating educational programs to promote urban agriculture and sustainability will be hit with a hurricane that floods their campus and wipes out the student projects that have just been completed. However, unexpected events may be an opportunity to model sustainability. How do we move forward and how do we learn from what has just happened? This particular disaster offers unique opportunities to discuss the role of climate change in large-scale natural disasters. What does the data say about connections between ocean temperature and hurricanes? If we embrace the narrative of sustainability that combines science, technology, and economics to create stable systems, how do build resiliency into our systems? Our future course discussions will encourage students to consider the role resiliency will play in the design of food systems and our future cities. Resiliency to natural disasters will be a requirement for creating future sustainable systems.

\section{Conclusions}

Reflections shared can assist others contemplating a summer program to teach urban agriculture and sustainability. At urban universities, students are rarely exposed to food production and sustainable technologies. An intense half-summer program with financial support allows students to justify their time spent in the program and can create an impactful experience. In the second year, we have made changes to combine curriculum, a hands-on project, and interdisciplinary student groups with professional development and mentoring. A hurricane at the end of our second summer reminds us that any educational program must be flexible. This particular disaster will be a mechanism for us to model resiliency with our students and will serve as a backdrop to discuss data and projections of climate change as it affects urban and agricultural systems. This hurricane that has devastated the Houston region is a stark reminder that any discussion of sustainability or sustainability plans must model resiliency for our changing planet.

\section{Acknowledgments}

We would like to acknowledge the hard work of the students in the 2017 EL CUAS program: Brayan Calvo, Sergio Diaz, Jonathan Garcia, Isaias Gonzalez, Sarah Graeber, Andrea Hain, Jennifer Herrera, Sara Lyons, Yarmilla Reyes, and Glen Wood. The external evaluation for this individual USDA project was performed by Drs. Caroline Szymeczek and Skip Bollenbacher, Integrated Learning Innovations, Inc. (info@ilearningi.com).

\section{References}

Cheruvelil, K. S., Soranno, P. A., Weathers, K. C., Hanson, P. C., Goring, S. J., Filstrup, C. T., \& Read, E. K. (2014). Creating and maintaining high-performing collaborative research teams: The importance of diversity and interpersonal skills. Frontiers in Ecology and the Environment, 12(1), 31-38. http://dx.doi.org/10.1890/130001

Clark, P. G. (2006). What would a theory of interprofessional education look like? Some suggestions for a theoretical framework for teamwork training. Journal of Interprofessional Care, 20(6), 577-589. http://dx.doi.org/10.1080/13561820600916717

Federal Emergency Management Agency [FEMA]. (2017, September 1). Federal government continues response to Hurricane Harvey [Press release]. Retrieved from https://www.fema.gov/news-release/2017/09/01/federalgovernment-continues-response-hurricane-harvey

Intergovernmental Panel on Climate Change [IPCC]. (2012). Managing the risks of extreme events and disasters to advance climate change adaptation (A Special Report of Working Groups I and II of the Intergovernmental Panel on Climate Change) [Field, C. B., Barros, V., Stocker, T. F., Qin, D., Dokken, D. J., Ebi, K. L,...Midgley, P. M. (Eds.)]. Cambridge, UK, and New York: Cambridge University Press. Retrieved from https://www.ipcc.ch/pdf/specialreports/srex/SREX Full Report.pdf 
Jacobi, M. (1991). Mentoring and undergraduate academic success: A literature review. Review of Educational Research, 61(4), 505-532. http://dx.doi.org/10.3102/00346543061004505

Hammer, L. B., Grigsby, T. D., \& Woods, S. (1996). The conflicting demands of work, family, and school among students at an urban university. The Journal of Psychology: Interdisciplinary and Applied, 132(2), 220-226. http://dx.doi.org/10.1080/00223989809599161

Klotz, L. (2016). Sustainability through soccer: An unexpected approach to saving our world. Oakland: University of California Press.

Krajcik, J. S., \& Blumenfeld, P. C. (2006). Project-based learning. In R. K. Sawyer (Ed.), The Cambridge Handbook of the Learning Sciences (pp. 317-333). New York: Cambridge University Press.

Mejia, B. (2017, May 9). How Houston has become the most diverse place in America. The Los Angeles Times. Retrieved from http://www.latimes.com/nation/la-na-houston-diversity-2017-htmlstory.html

Merchant, C. (2013). Reinventing Eden: The fate of nature in western culture (2nd Ed.). Abington, UK, and New York: Routledge.

National Hurricane Center. (2017, August 29). Tropical Storm Harvey Discussion Number 36. Retrieved from http://www.nhc.noaa.gov/archive/2017/al09/al092017.discus.036.shtml

Thayer, P. B. (2000). Retention of students from first generation and low income backgrounds. Opportunity Outlook: The Journal of the Council for Opportunity in Education. Retrieved from http:// files.eric.ed.gov/fulltext/ED446633.pdf

U.S. Department of Agriculture, Economic Research Service [USDA ERS]. (n.d.). Food Access Research Atlas: Documentation. Retrieved October 8, 2017, from https://www.ers.usda.gov/data-products/food-access-researchatlas/documentation/

University of Houston-Downtown [UHD]. (2016). About UHD: Mission and vision. Retrieved September 2017 from https://www.uhd.edu/about/Pages/about-mission.aspx

UHD. (2017). About UHD: UHD quick facts. Retrieved September 2017 from https://www.uhd.edu/about/Pages/about-quickfacts.aspx 